América sin Nombre, n.o 23 (2018): 145-155

DOI 10.14198/AMESN.2018.23.11

ISSN: 1577.3442 / eISSN: 1989-9831

Fecha de recepción: 28/05/2018

Fecha de aceptación: 02/07/2018
Modo de citación de este artículo:

Ballester Pardo, Ignacio. «La poesía mexicana vista desde España: puntos de partida y encuentro en dieciocho años». Madurez de la joven poesía mexicana. Alejandro Higashi e Ignacio Ballester (coordinadores). América sin Nombre, 23 (2018): 145-155, DOI: 10.14198/AMESN.2018.23.11

Link para este artículo: http://dx.doi.org/10.14198/AMESN.2018.23.11

\title{
La poesía mexicana vista desde España: puntos de partida y encuentro en dieciocho años
}

\author{
Mexican poetry seen from Spain: \\ points of departure and encounter in eighteen years
}

\author{
Ignacio Ballester Pardo* \\ Universidad de Alicante
}

\section{Resumen}

Un estudio sobre poesía mexicana contemporánea desde España permite advertir las conexiones literarias entre dos países que comparten lengua, referentes y problemas. Durante el tercer milenio la lírica viene condicionada, en parte, por becas, premios, editoriales, antologías, universidades y poéticas. Dicho contexto nos ayuda a entender los paralelismos que se generan a ambos lados. Los proyectos que se comprometen con lo social no son respaldados por el Estado, pero terminan siendo reconocidos con importantes galardones. Asimismo, las pequeńas editoriales ofrecen en México una amplia variedad de textos que nadie lee y casi nadie critica. En Espańa existen algunos esfuerzos por recoger la vitalidad del género literario en la capital del idioma; no obstante, la universidad puede ayudar a acercar esas constelaciones poéticas a un público escaso que continúa basándose en una división maniquea de lo que es joven y maduro.

Palabras clave: poesía en lengua española, beca, premio, editorial, antología, universidad, poética, siglo Xxi

\begin{abstract}
A study on the contemporary Mexican poetry from Spain allows to notice the literary connections between two countries that share language, references and problems. During the third millennium, the lyric becomes conditioned, in part, by grants, awards, publishers, anthologies, universities and poetics. This context helps us to understand the parallels that are generated on both sides. Projects that are committed to the social are not supported by the State, but end up being recognized with important rewards. Likewise, small publishers in Mexico offer a wide variety of texts that nobody reads and almost nobody criticizes. In Spain there are some efforts to capture the vitality of the literary genre in the capital of the language; nevertheless, the university can help to bring these poetic constellations to a scarce public that continues to be based on a Manichean division of what is original and mature.
\end{abstract}

Keywords: poetry in Spanish language, grant, award, editorial, anthology, university, poetics, 21st century

* http://orcid.org/0000-0002-5826-3167

Doctor en Filosofía y Letras por la Universidad de Alicante. Es miembro del Seminario de Investigación en Poesía Mexicana Contemporánea. Recientemente publicó con Alejandro Higashi «Tachaduras y borraduras en la poesía mexicana contemporánea (Albarrán, Herbert, Alcantar)» en el número 25 de la revista Signos Literarios. En la actualidad lleva a cabo una estancia posdoctoral sobre experimentalidad poética en la Benemérita Universidad Autónoma de Puebla. 
Actualmente nos podemos asomar sin dificultad a la poesía que se escribe en otro país. Más aún si se comparten lengua, historia y referentes; como es el caso de México y España. Sin embargo, debemos de tener en cuenta ciertos condicionamientos para entender cómo se lleva a cabo el trasvase y cuáles son las influencias y los diálogos que se establecen en la mayoría de edad del tercer milenio a ambos lados del Atlántico. Para ello estudiaremos algunos casos particulares que van de Balam Rodrigo o Esther M. García a Luis Bagué o María Sánchez, con el objetivo de trazar un panorama del estado actual de las editoriales y del trabajo de poetas jóvenes, así como de la crítica de México a España.

Ya en el siglo xv la Península Ibérica impuso con el idioma una filosofía que permea en los textos que van de Nezahualcóyotl a Sor Juana Inés de la Cruz. Por un lado, tenemos acceso mayoritario a los poemas del tlatoani (monarca) de Texcoco a través de las traducciones en espańol; mientras que la monja jerónima escribe en México mediante su mecenas, la virreina María Luisa Gonzaga Manrique de Lara. Vendría con el Modernismo americano la principal enseñanza para la lírica del siglo XIX en español, tal como lo señala José Vicente Anaya en un trabajo único sobre la vinculación que nos ocupa, «España en México y México en España. Banquetes que han compartido la poesía», fechado en 2003 y publicado en Círculo de Poesía:

De aquí en adelante, al menos en poesía, España dejó de ser la «Madre Patria» para, con la americana mayoría de edad [sic] llegar a ser simplemente hermana, y los poetas a tratarse entre sí como iguales. En esta ocasión se invirtieron los papeles dependentistas del pasado, pues la frescura literaria renovadora llegó de América a España (en línea).

En la época reciente, España llega a México por la Guerra Civil. En el segundo tercio del siglo xx arriban miles de personas que terminan siendo acogidas en gran medida en la antigua Tenochtitlan. Más que las generaciones de Contemporáneos, Estridentistas, Poeticistas o Infrarrealistas, quienes por un tiempo influyen en buena parte de la poesía mexicana contemporánea son los espańoles que llegan tras el conflicto fratricida y conforman la tradición de la poesía contemporánea ( $\mathrm{Paz} 298$ ). Al promover con libertad diversos proyectos editoriales, confluyen en el imaginario cultural y social hasta el punto de convertirse en lecturas obligadas para el currículo y la cultura popular. Exiliados españoles en México como
Concha Méndez, Juan Gil-Albert, Luis Cernuda, Rafael Alberti, los Díez-Canedo, Ramón Xirau, Tomás Segovia o José Pascual Buxó -según lo estudia recientemente Pedro García Cueto (2016)-, y también quienes no lograron llegar en vida -como Miguel Hernández (Ballester 2018)-, integran la herencia más cercana del Colegio Madrid, el Instituto de México en España, El Colegio Nacional o la Academia Mexicana de la Lengua.

En el siglo xxi la lírica se mueve y puede hasta pervertirse por el desarrollo del Fondo Nacional para la Cultura y las Artes (FONCA), las becas y premios que permiten la conexión entre México y España, la creación de editoriales independientes que se valen de nuevos canales de escritura y de lectura y de difusión, la frecuencia con que en ambos países se publican antologías no libres de polémica, los convenios entre universidades de Iberoamérica o la ruptura y la continuidad de poéticas que tienen más partidas que puntos de encuentro.

\section{Un envidiable sistema de becas}

Cincuenta años después del 68, no hay duda de que la dilución en México de lo que tradicionalmente se entiende por poesía social coincide con el anclaje del suculento sistema de financiación pública para quienes escriben. Con la creación del FONCA en 1989 se destina parte importante del presupuesto estatal a la manutención de poetas que previamente solicitan la ayuda económica a través de un proyecto que va a condicionar la forma del poemario. Este se publicará sin apenas lectores y normalmente estará lejos del compromiso que de modo particular siguen representando Enrique González Rojo Arthur u Óscar de Pablo. "Quienes nacieron entre 1975 y 1985 están muy alejados del compromiso social» (Higashi, «Hitos provisionales...» 63). Poetas de 18 a 34 años de edad pueden desempeñar así su labor gracias a becas económicas, tutorías con artistas de reconocido prestigio o encuentros de jóvenes que crean para un fomento interdisciplinar. Ahora bien, el que parecía un método preciso para controlar la insurrección de incipientes poetas en edad de rebelarse dará con algunos comportamientos de excepción.

Las siete décadas de gobierno del Partido Revolucionario Institucional (PRI) que pusieron fin al siglo Xx nos hacen pensar en la dictadura franquista. Salvando siempre las distancias, los poemas que denunciaban la Matanza de Tlatelolco en No me preguntes cómo pasa el tiempo (1969) de José Emilio 
Pacheco o la desaparición de los 43 de Ayotzinapa con la crónica de Procesos de la noche (2017) de Diana del Ángel podrían encontrar sus correspondencias en la inapetencia temporal de Jaime Gil de Biedma en Poemas póstumos (1968) o la crítica a una crisis de naciones que Luis Bagué ofrece en Clima mediterráneo (2017). Por una parte, José Emilio Pacheco retoma en su poema "Manuscrito de Tlatelolco» las voces que se oyeron el 2 de octubre en la Plaza de las Tres Culturas sirviéndose de «textos traducidos del náhuatl por Ángel María Garibay y publicados por León-Portilla en Visión de los vencidos sobre la conquista de México» (Alemany, Poética coloquial hispanoamericana 109), además de "La noche de Tlatelolco de Elena Poniatowska y un artículo publicado en Siempre! de José Alvarado» (Alemany, Poética coloquial hispanoamericana 109). En ese momento, poetas de la posguerra espańola como Gil de Biedma sellaban una moral que no regresaría más que en la denuncia implícita y culta que vemos ahora con Luis Bagué y su irónico retrato de la identidad española y europea a espaldas de los refugiados. El también crítico estudió la evolución de este tipo de poesía ajena a las becas en su igualmente distinguida tesis doctoral: Poesía en pie de paz. Modos del compromiso hacia el tercer milenio (2006). Pese al difícil reconocimiento que tiene lo social en la literatura, su último poemario recibió el Premio de la Crítica, además del XXX Premio Tiflos de Poesía. En este sentido nos encontramos con otra excepción en México: la poeta e investigadora Diana del Ángel, becaria de la Fundación para las Letras Mexicanas en el área de poesía, de 2010 a 2012, se atreve a "reconstruir» el rostro de Julio César Mondragón y a develar la historia de los 43, tal como lo reconoce Elena Poniatowska en el prólogo de Procesos de la noche; y así lo hicieron también Verónica Gerber Bicecci, Luis Felipe Fabre y Luis Jorge Boone para seleccionarlo como proyecto ganador de la Primera Residencia Ventura + Almadía para la Creación Literaria. Esta beca, como se explica al final del libro, le facilitó a la autora «una estadía de dos meses en la Ciudad de Oaxaca, México, así como las condiciones necesarias para poder dedicarse de tiempo completo a la conclusión de su obra» (207).

Si la única manera de vivir de la escritura siguen siendo las prebendas públicas o privadas, si en el tercer milenio existen múltiples canales (con especial atención a internet) para lo que la convención ha etiquetado de social, si es cierto que prima el discurso intimista de quienes se alejan de un casi inexistente público lector, también advertimos obras que merecen atención sin desvincularse del contexto y sin montarse en la tragedia, como podríamos pensar que ocurre al leer Memorial de Ayotzinapa (2016) de Mario Bojórquez.

Desde España vemos cómo en México hay poetas que pueden dedicarse por entero a la escritura, al menos durante un tiempo: «No hay que olvidar que soy una puta: tengo una beca, el gobierno mexicano me paga mes con mes por escribir un libro» (Herbert 42); pero dicha burbuja artificial acaba estallando y provocando discusiones que olvidan, salvo casos particulares, el poemario y se centran en el proyecto, en intereses y en experiencias que tendrían de manera esporádica su correlato español en la Xarxa Vives $o$ en la Fundación Antonio Gala, donde trabaja la poeta oaxaqueña Clyo Mendoza durante el curso 2018-2019.

\section{El canon a través de los premios}

A falta de una crítica sólida, los premios de poesía se erigen como única vara de medir algo que casi nadie lee. La importancia literaria que tuvo el Premio Xavier Villaurrutia en el siglo pasado se concentra ahora en el Premio Bellas Artes de Poesía Aguascalientes: sin duda, el galardón que más calado tiene en México. Con sus cincuenta ediciones marca, si no un canon, sí una perspectiva para las obras galardonadas. El hecho de que solo lo hayan recibido nueve mujeres señala la desigualdad y la contradicción que existe en eventos donde son ellas las que más presencia tienen como oyentes y ponentes, al menos en las últimas décadas. Además, quienes reciben el premio no siempre terminan siendo las voces más influyentes en el devenir del género; de ahí que no debamos olvidar los distintos tipos de canon: editorial, comercial, canon editorial no comercial, etc. (Higashi, PM / $X X I / 360^{\circ}$ 26-27). La institución que reconoce tal obra nos condiciona en su lectura. Así ocurrió en 2010 con Libro del abandono de Javier Acosta, que recibió el Aguascalientes a la vez que se abría una polémica todavía candente en torno a la convención del tipo de poesía que merece ciertos premios; o viceversa: premios que recaen (en México y en Espańa) sobre una determinada variedad (que por reiteración acaba siendo homogeneidad) poética. Y es que la validación de una obra atiende básicamente a dos preceptos: su vinculación con la temática social (de manera opuesta a las becas) o una apuesta formal efectiva (como la técnica del desdoblamiento que fijó Francisco Hernández y continúa Christian Peña). Además, según apuntaba Jorge Aguilera en 
el Coloquio 50 Años Premio Bellas Artes de Poesía Aguascalientes, el jurado al fin y al cabo está formado por poetas que mantienen una estrecha relación con la estética que se legitima a través de la percepción que una obra recibe por ser galardonada a partir en buena medida, no lo olvidemos, del gusto de quienes votan, reconocidos anteriormente con tal distinción.

Pese a las bases restrictivas de tales certámenes, en los últimos años se amplían las posibilidades para participar con textos que no atiendan a un límite de cuartillas, aunque continuamos obviando propuestas más allá de la página. En cuanto a la lengua, desde el nombramiento a Balam Rodrigo como acreedor del Premio Bellas Artes de Poesía Aguascalientes 2018 con su Libro centroamericano de los muertos (2018), se permite el envío de trabajos en lenguas originarias. Ahora bien, hay que adjuntar su correlato en español. Por tanto, seguimos pidiendo y leyendo traducciones, que competirán con textos garantes del ritmo, la sintaxis o la sonoridad del original. Tales restricciones facilitan el fallo del jurado al tiempo que impiden la equidad y la libertad formal (que también resulta temática) de una irremediable evolución del género lírico a ambas orillas.

La parafernalia del premio garantiza una buena bolsa económica, pero no siempre hace lo propio con la promoción editorial. Prueba de ello es el vaivén que existe con Joaquín Mortiz, Ediciones Era o Fondo de Cultura Económica en la ciudad hidrocálida. A pesar de no asegurar con la fuerza del de Aguascalientes una presencia canónica en el panorama nacional, el Premio Internacional Manuel Acuña de Poesía en Lengua Española es el que cuenta con un mayor monto: ciento veinte mil dólares. Llama la atención que la cifra ascienda en dólares cuando lo convoca el Gobierno del Estado de Coahuila de Zaragoza. También sorprende que en su quinta edición, en 2017, lo recibiera por primera vez una española: Ana Isabel Conejo, por Todo lo abierto. El furor que causó la noticia se ha disipado antes de la publicación de la obra. También fue breve, aunque intenso, el impacto que en 2018 tuvo Enrique González Rojo Arthur al rechazar ser postulado para el Premio Nacional de Artes y Literatura, a través del FONCA, debido a que era el hasta entonces presidente Enrique Peña Nieto el encargado de entregarlo.

La cantidad de premios que hay en México no dista demasiado de la que encontramos en España. A un lado destaca el Premio Internacional de Poesía Gilberto Owen Estrada, con una docena de convocatorias, por la Universidad Autónoma del Estado de México; al otro, el Premio Internacional de Poesía
Fundación Loewe, superando las treinta ediciones, publicado en Visor. Ambos permiten participar sin restricción de nacionalidad o residencia. Sin embargo, en América se canoniza un premio por quienes lo han recibido, es decir, a posteriori, como diría el poeta yucateco -Cincinnatis next poet laureate-Manuel Iris: «El premio Carlos Fuentes mereció un Lizalde» (Flores, Facebook en línea); mientras que en Europa se sigue (el verbo no implica leer) a poetas que a priori han recibido una buena cantidad de galardones. Por ejemplo, la joven pero ya sólida voz de Esther M. García, en el reciente Gilberto Owen por Mamá es un animal negro que va de largo por las alcobas blancas (2018), afamó el premio para quienes vivimos en España y mostró la violencia de las mujeres al norte del país, a la vez que el también joven y reconocido Ben Clark ganaba aún más enteros por el Loewe con La policía celeste (2018), la intrahistoria del amor como sentir general. Antes, García recibió el Premio Nacional de Poesía Joven Francisco Cervantes Vidal 2014 por el dolor materno de Bitácora de mujeres extrañas y fue becaria del FONCA. Clark, con Los hijos de los hijos de la ira (2006), mostró el cambio generacional -con el que cerraremos- y obtuvo el Premio Hiperión ex aequo con David Leo García. El español de origen británico publicó en México Los últimos perros de Shackleton (2013), poniéndose en la piel del explorador angloirlandés Ernest Shackleton a través del poema de la alteridad que cultivan Francisco Hernández en Mar de fondo (Premio Aguascalientes en 1982) o Christian Peña en Me llamo Hokusai (Premio Aguascalientes en 2014). Por su parte, la chihuahuense presenta el resto de sus poemarios en formato digital y abierto a través del archivo de Poesía Mexa que veremos a continuación.

\section{Los contrastes editoriales}

Los grandes sellos controlan el mercado editorial en cualquier producto. De México sobrecoge la desigualdad. El Fondo de Cultura Económica o la Secretaría de Cultura (antigua Conaculta) cuentan en sus catálogos con parte importante de la poesía mexicana y espańola. La editorial Planeta trata ahora de vender la «nueva poesía» en España. La diferencia sigue siendo el respaldo del Estado. La apertura de Visor en México con Valparaíso Ediciones posibilita un cambio para una colección que, si en su día conectó a España con la literatura hispanoamericana, va ofreciendo un catálogo cada vez más discutible. Las ya 
no tan pequeñas apuestas de Bonobos (con Santiago Matías), Filodecaballlos (con León Plascencia Nol), Mantis Editores (con Luis Armenta Malpica), Verso destierro (con Adriana Tafoya), Malpaís Ediciones (con Iván Cruz), Cuadrivio (con Alejandro Baca) o Pre-Textos (con Manuel Borrás), La Bella Varsovia (con Elena Medel), Delirio (con Fabio de la Flor), La Isla de Siltolá (con Javier Sánchez) y Torremozas (con Marta Porpetta) intentan equilibrar un mercado que cierra pronto. Ante tal desventaja resulta un bálsamo el trabajo que Luis Eduardo García, Diana Garza Islas, Daniel Bencomo, Yolanda Segura y Jorge Posada llevan a cabo en el Archivo de Poesía Mexa: un repositorio de poesía mexicana en formato digital y abierto donde es posible encontrar libros y obras de medio centenar de poetas recientes. Dicho fondo genera una visibilidad rápida y cómoda de la poesía mexicana cuando todavía no se puede sortear los complejos envíos editoriales; pues, en algunos casos, el producto digital se encuentra con la traba de un inadmisible cambio de moneda. La liberación de archivos, tan poco común en Espańa, permite leer textos descatalogados y reunir en la lírica una vuelta más del «signo en rotación» que ilustra Tania Carrera en Un dios lubricante (2015) o el formato de videojuego que Minerva Reynosa presenta en Mammut (2015), innovaciones propias de la poesía experimental que Ulises Carrión o Rocío Cerón han ido acercando a España a través de múltiples proyectos y estancias internacionales.

La residencia de poetas de México en España ha servido a Silvia Tomasa Rivera para homenajear a Santa Teresa de Jesús: En el huerto de Dios (2014). Lo escribió con una beca del Sistema Nacional de Creadores de Arte FONCA (2009-2012) y comienza con «Mi agradecimiento al Gobernador de Veracruz Javier Duarte de Ochoa por el apoyo que me otorgó para mi residencia en España» (7), dando reconocimiento a la Universidad Autónoma de Nuevo León también como editorial. Este mismo tema le sirvió a Minerva Margarita Villarreal para merecer el Aguascalientes tras el quinto centenario de la monja de Ávila con Las maneras del agua (2016). Asimismo, destaca la publicación del chiapaneco Efraín Bartolomé en Balduque. Dicha editorial cartagenera preparó una antología amorosa, Cabalgar en las alas de la tormenta (2015), que el poeta mexicano fue presentando por la geografía española de la mano de Noelia Illán. La también poeta espańola, junto a Joaquín Baños, Vanessa Castaño, Samuel Jara, Daniel J. Rodríguez y Sara J. Trigueros, formó parte hasta 2018 de La Galla Ciencia, revista de poesía que en sus ocho números y en su portal electrónico acercó México a España con una independencia de la que no gozan Tierra Adentro o Nexos. Asimismo, el poeta mexicano Carlos Ramírez Vuelvas, Doctor por la Universidad Complutense de Madrid y Secretario de Cultura de Colima, escribió parte de su obra en España, recibiendo el Premio de Ensayo Caja Madrid por su libro Mexican Drugs. Cultura popular y narcotráfico (2011). Por otro lado, a la manera del albanés radicado en México Xhevdet Bajraj, el cantautor aragonés Ángel Petisme defiende un hondo compromiso social en El sur del tiempo (Antología poética 1984-2015) (2015) de la mano del sevillano Manuel Pérez-Petit y su editorial Sediento en México.

Los ejemplos a ambos lados son numerosos, más si cabe con el rescate que están haciendo, también desde Sevilla, la editorial Renacimiento o, ya en Barcelona, Ultramarinos. No obstante, los casos apuntados hasta ahora permiten comprobar el intercambio poético existente entre dos países: el que da nombre a la lengua y el que más hispanohablantes tiene. Por su amplitud, podría parecer que Círculo de Poesía y más recientemente Oculta Lit no se adscriben a México o España, pero las cifras acaban marcando la desigual carrera de las letras.

\section{Las repetidas antologías}

No vamos a contar quién aparece o se obvia en las constantes antologías de poesía en lengua española que se suceden en el siglo xxI. Únicamente nos detendremos en casos específicos que explican cómo se articula la lírica mexicana desde España.

Herederas inmediatas de Antología. La poesía del siglo XX en México (2009) que Marco Antonio Campos prepara para Visor -y con más difusión que el trabajo de Antonio Orihuela en 21 Balas: Antología de poesía mexicana actual (2009)-, dos son las muestras señeras que se imprimen en España para ponernos al día de lo que está ocurriendo al otro lado: Los reyes subterráneos. Veinte poetas jóvenes de México (2015), coordinada por Elena Medel y Luna Miguel en la editorial que dirige la primera, La Bella Varsovia; y Sombra Roja. Diecisiete poetas mexicanas (1964-1985) (2016), que Rodrigo Castillo arma en Vaso Roto. Las poetas, ensayistas y editoras españolas recogen en Los reyes subterráneos el catálogo propositivo de quienes nacen en México entre 1985 y 1994. Con veinte, treinta años de edad ya descuellan las citadas Esther M. García y Diana Garza Islas y la prometedora Clyo Mendoza, la más joven 
en recibir el Certamen Internacional de Literatura Sor Juana Inés de la Cruz. También destacan Jehú Coronado, David Meza o Dante Tercero -este último polémico por su proyecto de escritura con emoticonos llamado «Poemojis» y acreedor de una beca del FONCA- en un siglo en el que la poesía mexicana la escriben las poetas (ni poetisas ni poetas mujeres). Así lo reivindica Sombra roja, volviendo a la "generación» anterior que estudiaban Medel y Miguel -reconociendo un incipiente impacto literario de México en la poesía española a través de Roberto Bolaño-. El poeta, ensayista y editor mexicano Rodrigo Castillo selecciona rigurosamente las voces más influyentes. Y aquí juega a su favor el colchón de años, mínimo pero suficiente, para señalar un canon que atiende a la lengua zapoteca de las oaxaqueñas Natalia Toledo e Irma Pineda, a la poesía experimental de Mónica Nepote, Rocío Cerón o Karen Villeda, al testimonio de Maricela Guerrero, Sara Uribe o Xitlalitl Rodríguez, a la transparencia verbal de Paula Abramo o a la poética de la desapropiación que construye la voz más representativa a nivel internacional, Cristina Rivera Garza. De los últimos años, poetas más recientes y ya en proceso de consolidación en ambos países forman Fuego de dos fraguas: poetas jóvenes de México y España (2016).

Las recopilaciones acostumbran a repetir nombres, y hasta poemarios. Es por ello que temporalmente se delimitan grupos poéticos que, según veremos, ya no se mantienen en la convención del término "generación». Otras antologías de poesía mexicana fuera de México: la que en Chile preparan Pedro Serrano y Carlos López Beltrán para perforar una vez más la tierra húmeda, alegoría de la madurez de la joven poesía mexicana, 359 Delicados (con filtro). Antología de la poesía actual en México (2012); o la que en Francia alimenta la polémica de para qué y cómo distribuye el Estado los fondos públicos, titulada México 20. La nouvelle poésie mexicaine (2016) y coordinada por Jorge Esquinca, Tedi López Mills y Myriam Moscona. Debido a las paradójicas dificultades de la industria editorial que ya señalamos, las muestras de las mencionadas revistas La Galla Ciencia, Círculo de Poesía u Oculta Lit motivan la creación de trabajos en papel y en formato digital como el que reúnen para la Secretaría de Educación Pública Armando Salgado y José Agustín Solórzano en Parkour pop.ético (o cómo saltar las bardas hacia el poema) (2017). Curiosamente, desde la capital, desde la Ciudad de México, se establece una agrupación de poetas por Estados a favor de una descentralización.
Tales recopilaciones definen qué leemos cuando hablamos de poesía mexicana contemporánea. Urge investigar lo contemporáneo para restablecer el canal entre la numerosa nómina de poetas y el mermado público lector: «Los críticos literarios son poquísimos contra la enorme cantidad de escrituras que se suscriben y disipan en la liquidez algorítmica de la interface» (Castillo 255). Jóvenes poetas requieren, pues, una crítica de lo estético y lo comunicativo para distinguir la poética efectista que funciona al postular un premio o al ser una y otra vez retuiteada. Repetir antologías sin más no enriquece el panorama literario. Debemos de recordar qué propone un poema, por qué logra conectar o no con el público lector y, por supuesto, cómo influyen los aspectos relativos a la sociología poética, en este caso, de México y España.

\section{La necesidad de las universidades}

En ocasiones, el respaldo de la academia pone el foco más en intereses personales que en una verdadera necesidad social. Este cliché motiva investigaciones sobre obras o temas alejados de la mayoría. Los trabajos responden a charlas entre círculos internos que perpetúan un sistema endogámico. Joaquín Díez-Canedo F., Director General de Publicaciones y Fomento Editorial de la Universidad Nacional Autónoma de México (UNAM), se opone a ello en su artículo «Algunas consideraciones sobre la edición universitaria», publicado en Encuentros 2050: «Aún en los temas más regionales, esta conversación suele involucrar a investigadores de distintas universidades en varios países, resultado de intercambios y relaciones académicas establecidas durante posgrados en el extranjero. En México se añade además el hecho de haber acogido tantas inmigraciones» (38). La relaciones culturales, sociales, económicas, políticas y hasta estéticas entre España y México crecen con los vínculos de las instituciones educativas. La perspectiva -que no exégesis- de un variado panorama de poemas cargados de referencias intertextuales permite romper la distancia entre la atrofia lectora y poetas cada vez más presentes en la academia; tal como ya lo probaba Vicente Quirarte en 1982 a propósito de su generación, la de los cincuenta.

Los primeros poemas de algunas de las voces más destacadas de la actualidad vieron la luz gracias a Punto de Partida, la revista para jóvenes de la UNAM. En la Ciudad de México la Universidad Autónoma Metropolitana también destina partidas y 
organiza encuentros en pos de la poesía. En el ámbito privado, la Universidad del Claustro de Sor Juana o la Universidad Iberoamericana legitiman la importancia que sigue teniendo la capital como núcleo de una constelación que se va abriendo -como ocurre con Madrid y su conexión con Granada, Barcelona o Salamanca- en Estados, principalmente, del norte: Coahuila, San Luis Potosí, Jalisco o Querétaro. En la frontera de EUA, San Diego o El Paso convocan habituales eventos en torno a la poesía, debido en parte a la presencia de académicas y académicos de México que también se dedican a dicho género literario. Otras instituciones se vinculan, como veíamos, a premios, becas, estancias o ferias vitales para el intercambio de poetas entre México y España. Recordemos que las dos últimas ediciones de la Feria Internacional del Libro de Guadalajara, las trigésimo primera y trigésimo segunda, estuvieron dedicadas a la Península Ibérica, a Madrid y a Portugal, respectivamente. A la inversa, en territorio espańol, únicamente se celebran eventos puntuales como el del Festival «México se escribe con equis». Ambos países, en cambio, sí tienen en común la injusta sostenibilidad de las universidades a base de contratos temporales y precarios de docentes que tratan de seguir escribiendo.

Si los espacios académicos no se abren al extranjero y a otros géneros literarios, el ensimismamiento de un texto tradicionalmente hermético causa $E l$ ocaso de los poetas intelectuales y la "generación del desencanto» (2010) o la búsqueda De la intimidad. Emociones privadas y experiencias públicas en la poesía mexicana (2016): libros de Malva Flores y Luis Vicente de Aguinaga, poetas que se dedican a la academia con una necesaria conciencia ética y estética. Las estancias que de manera exigente ofertan los gobiernos de ambos países o entidades privadas como el Banco Santander ponen en contacto a universidades y así, a poetas; y, ojalá, al público lector.

\section{Una poética doble y desigual}

En uno de los convenios entre universidades de España y México, Carmen Alemany coordinó el que hasta ahora es el estudio más completo sobre la reciente poética mexicana que en la práctica define el género literario: Artes poéticas mexicanas (de los Contemporáneos a la actualidad (2015). En dicho libro, publicado en la Universidad de Guadalajara, se incide en lo que nos dice sobre la poesía el propio poema, aunque «[a]nte un momento histórico tan diversificado y poliédrico, los antiguos y recientes cánones resultan insuficientes a la hora de fijar los parámetros de las obras artísticas y en concreto de las poéticas» (Alemany, Artes poéticas mexicanas 46). La disgregación de poetas y de las maneras de entender el poema, junto a la dispersión geográfica, la lengua común y la influencia de las redes digitales en las lecturas, igualmente desde la academia, generan oportunidades para profundizar en la lírica también desde la docencia. Terminaremos, por tanto, señalando casos actuales que permiten unir variables y leer la poesía mexicana a ojos de la española (a la vez que conocemos la espańola a partir del movimiento en México).

Tal como lo hemos visto en este número de América sin Nombre con Ignacio Ruiz-Pérez y Alejandro Higashi, dos son las vertientes (vinculadas) que tomamos de la poesía mexicana: el coloquialismo que van heredando de José Emilio Pacheco y el dificultismo (Palma Castro) con que asombra Gerardo Deniz. Este último, de origen español, es el mejor poeta de México para críticos como Fernando Fernández, también poeta mexicano de raigambre peninsular; aunque es la primera la voz que más reconocimiento tiene en España y en el tono, en las formas y en la intertextualidad de los poemas venideros. Quien copa las exangües listas de poetas de España en México, el reciente Premio Internacional de Poesía Ramón López Velarde, Luis García Montero, sostiene que "[l]a poesía es la capital de un idioma sin centros. Algo que puede comprobarse con afortunada claridad al pensar en nuestro idioma» (Montero apud Campos 382). Ahora bien, el actual director del Instituto Cervantes no es el único que vertebra esta poética: doble, de ida y vuelta, y desigual por la descompensada conciencia que una tiene de la otra.

El ecologismo que profesa el Premio Reina Sofía y Premio Cervantes en 2009, José Emilio Pacheco, lo activa Homero Aridjis y continúa en Jorge Riechmann o María Sánchez, cuyo primer poemario, Cuaderno de campo ([2017] 2018), ya en su décima edición resulta esperanzador para la poesía en Espańa por su regreso a lo rural y a un talento autónomo que se aleja de estereotipos o artificios facilones. Continuando de México a Espańa, el cáncer que siente y transmite Daniela Camacho -reciente Premio de Poesía Joaquín Xirau Icaza- reaparece en el verso quebrado de la hija que también lo recuerda, Alba Ceres. La misma esperanza irradian Eva Castañeda y Celia Corral Cañas al cultivar y estudiar las formas de la enunciación que han ido proponiendo Karen Villeda a un lado y Vicente Luis 
Mora al otro, la genuina sintaxis de Hernán Bravo Varela o Carmen Juan, el dolor de la muerte voluntaria que reverbera en Alejandro Tarrab o Ramón Bascuñana, así como la oculta cotidianeidad de Alí Calderón y Fernando Valverde o el testimonio de Sara Uribe y Luna Miguel.

En México, el concepto de generación que afianzaron Taller o Vuelta se ha ido disgregando para enriquecer manifiestos que solo continúan en grupos como Los Kikín Fonsecas y el Gringo Castro (KFGC): un colectivo de lo que podríamos llamar poesía multimedia, formado por Gerardo Ocejo, Rodrigo Román, Andrei Vásquez, Jorge Sosa, Ánuar Zúñiga y Oliver Hinchastegui, cuya serie Los Fotocopiadores retrata el estado actual de la poesía en México. Nos encontramos ahora ante constelaciones (Higashi, PM / XXI / 360 362) que se conectan y coinciden en la dispersión de una edad efímera. Mientras, en España se suscita una polémica que abisma el trabajo de Javier Krahe, Olvido García Valdés, Luis Antonio de Villena, Juan Carlos Mestre y una amplia nómina que regenera la poesía de la experiencia o la otra sentimentalidad y la poética novísima (hasta, por ejemplo, Juan Antonio González Iglesias o Berta García Faet) del, por otro lado, éxito adolescente y virtual de Elvira Sastre, Marwan, Irene X o Loreto Sesma.

En una entrevista para La Galla Ciencia, el poeta mexicano Juan Carlos Bautista le confesaba a Aitor Francos: «desgraciadamente no conozco casi nada de la poesía española actual. Es una desgracia, pero la poesía iberoamericana, en la era de la internet y de las redes sociales, está más aislada que nunca» (en línea). Y es que «[e]n medio de una poesía joven que tarda mucho en madurar y que tiene tantos referentes que (no ordenados) parece, a ratos, que no tuviera ninguno» (de Villena en línea), la llegada desde México a España de Roberto Bolaño, Jordi Soler, Juan Villoro, Juan Pablo Villalobos o, en los últimos años, de los jóvenes Tońo Magaña o Yanine Villalobos, siempre por el este de la Península, por el Mediterráneo y no por el Atlántico, parece confirmar que nos empeńamos en tomar la distancia más lejana entre ambas poéticas.

\section{Hacia una conclusión temprana}

El acotamiento de becas, premios, editoriales, antologías, universidades y poéticas desde varios ejemplos de México y España muestra cómo se vinculan y superponen condicionantes que ya pertenecen de manera innegable al género de la lírica y, por extensión, a la literatura.

La escasa crítica de poesía en español parte de quienes la crean. Quienes la leen, por lo general, son quienes la escriben. La relación editorial entre México y España permite que diversas obras conformen los dos catálogos internacionales, recibiendo premios a ambos lados como es el caso de Canción de tumba (2011), título con el que Julián Herbert reúne otra de las características comunes que advertimos cual Colón comparando lo que ve con lo que cree conocer: la poesía convive ya por fin con demás géneros literarios, prevaleciendo la novela pero sin olvidar el ensayo o el teatro. Así pues, sirviéndonos de las ideas que se han ido articulando en este número de América sin Nombre, llegamos a la conclusión de que pese a las polémicas, la variedad o la intermitencia de la poesía mexicana (o precisamente por ello), desde Espańa tenemos la oportunidad de gozar de un género que en la Península se frenó en el siglo pasado, pese a constantes pero incontrolados y efímeros coletazos. Los sellos con más peso apuestan por poetas canónicos y las pequeñas editoriales se ven obligadas a cerrar si buscan renovar el género. España se fija en jóvenes que influyen en las redes sociales para proponer una nueva poesía coloquial que choca y asombra a quienes ya maduraron y aborrecen el efectismo adolescente. México se avienta con numerosas editoriales periféricas que apenas consiguen el impacto de una capital que paulatinamente, sin público lector, va descentralizándose.

Las constelaciones de las que nos hablan Belem Clark de Lara, Josu Landa o Alejandro Higashi van perdiendo el centro, en parte, por la desaparición de fronteras más allá de las lingüísticas. Pese a la complejidad y la variedad del canon, la academia debe de estudiar casos particulares que sean representativos de la conciencia ética y estética del poema que navega en la red; libre, cada vez más, de imposiciones formales por la beca o el premio que condicionan la obra de arte. ¿No sería más constructivo facilitar la participación en dichos certámenes desde una expresión original, sin restricciones formales; y de esta manera acercar la poesía a la sociedad? Existen ya demasiados trabajos que critican el sistema de becas y premios, pero no ofrecen propuestas diferentes. Las listas de poetas excluidos o incluidos en antologías y premios no ayudan más que a crear una polémica difícil de resolver. Uno de los caminos podría ser brindar criterios estéticos o comunicativos para cribar y seleccionar lo verdaderamente valioso de esa 
sobreoferta de nombres, editoriales y medios. No tratamos de autodestruir la labor crítica. Al contrario, dicho trabajo resulta fundamental para acercar un género y un público tan alejados en el siglo xxI; y tales criterios parten precisamente de la educación: ¿cómo conjugar el desinterés de la sociedad por la poesía con la honestidad que debe mantener el profesorado universitario dedicado a la formación de jóvenes futuros docentes y profesionales de la literatura? Todo ello pasa por hacer consciente a la sociedad de la necesidad de una educación estética, ética y espiritual desde la infancia; y no solo económicopragmática, como sucede actualmente. Si la poesía no vuelve a conectar con el público lector, si no se ofrecen desde la crítica las herramientas éticas y estéticas para establecer una comunión, el abatimiento de quienes escriben poesía transformará la ironía de sus primeros años en melancolía y, por último, en silencio; tal como lo estudia, a propósito del popularísimo Jaime Sabines, Ana Chouciño (2018), una de las investigadoras que más ha acercado la poesía mexicana a España.

Ese flujo que llegó tras la Edad Media de España a México, y que con el Modernismo fue de México a España, amaga con reproducirse después de que miles de jóvenes migraran hacia el país norteamericano debido a la crisis económica que se destapó en el Mediterráneo en torno al año 2008 y que terminó afectando, cómo no, a la sociedad y a la cultura. Las antologías, a veces temáticas, plasman tal problemática sin invertir demasiado en un libro que raramente se reimprime. Las universidades avalan la coedición de textos breves que en realidad se intercambian con mejor resultado mediante las plataformas virtuales. Pese a la instalación digital, la poesía regresa al papel para fijar proyectos que de otra manera no podrían justificarse o registrarse. Existe, pues, un desfase entre el inventario editorial y los modos de lectura. Si la performance no acaba integrando la estantería de una biblioteca o la caja de una bodega, ¿quién certifica que el proyecto llegó a buen puerto?

El libro de poemas evoluciona al poemario, especialmente en México, pues el proyecto requiere una obra conjunta. Esta continuidad contradice las lecturas fragmentarias que se comparten en las redes y contrasta una vez más con obras interdisciplinares que abandonan el texto tradicional y conviven con demás artes audiovisuales. ¿Cómo considerar dentro del género literario, al menos en España, una producción que no sigue ni el número de páginas ni el de palabras, sino que se basa en un acontecimiento? En México aún no tiene cabida, pero no hay duda, desde España, de que el atrevimiento y el horizonte americanos son mucho mayores que los de las grandes editoriales europeas que monopolizan la poética: exportan más que importan. Así lo demuestra el numeroso elenco de poetas de España que reconocen en México, mientras que al revés difícilmente acertamos a nombrar unos cuantos nombres que no hemos leído.

La universidad puede ser el cauce para restituir una investigación coetánea a los movimientos, en este caso, de la poesía actual. Comprendiendo lo cercano podremos atender e interpretar lo aparentemente distante, que no distinto: sino diverso. La madurez de la poesía mexicana contemporánea destaca aún más por su independencia, su rebeldía -de fondo y forma (aunque pertenecen al mismo plano)-, su vitalidad y su continuo legado cuando se compara o se ve desde un país que no termina de ser el adolescente que va pasivo de la mano de sus padres o, en el peor de los casos, el que se inquieta y huye corriendo el mismo camino y sin mirar atrás.

Un estudio práctico o un pequeño análisis comparativo desde los condicionamientos señalados repara en paralelismos sobresalientes en México y a penas notables en España. Resuenan de este modo más los puntos de partida que los encuentros furtivos, tenues y clandestinos de un género del que tenemos mucho que aprender.

\section{Bibliografía}

Acosta, Javier. Libro del abandono. México: Era / Instituto Cultural de Aguascalientes / Instituto Nacional de Bellas Artes, 2010.

De Aguinaga, Luis Vicente. De la intimidad. Emociones privadas y experiencias públicas en la poesía mexicana. México: Fondo de Cultura Económica, 2016.

Alemany Bay, Carmen. Poética coloquial hispanoamericana. Alicante: Universidad de Alicante, 1997.

Alemany Bay, Carmen. Artes poéticas mexicanas (de los Contemporáneos a la actualidad). Guadalajara: Centro Universitario de Ciencias Sociales y Humanidades, Universidad de Guadalajara, 2015.

Anaya, José Vicente. «España en México y México en España. Banquetes que han compartido la poesía». Círculo de Poesía. 2012 [ed. or. 2003]. Círculo de Poesía. Medio de publicación (web). <https://circulodepoesia.com/2012/07/banquetes-que-han-compartido-la-poesia/>. Consultado 8 my. 2018.

Del Ángel, Diana. Procesos de la noche. México: Almadía, 2017. 
BAllester, Ignacio. «La presencia de Miguel Hernández en la poesía mexicana contemporánea: del pueblo a la Universidad» [en prensa].

BAGUÉ, Luis. Clima mediterráneo. Madrid: Visor, 2017.

Bagué, Luis. Poesía en pie de paz. Modos del compromiso hacia el tercer milenio. Valencia: Pre-Textos, 2006.

Bartolomé, Efraín. Cabalgar en las alas de la tormenta. Cartagena: Balduque, 2015.

Bojórquez, Mario. Memorial de Ayotzinapa. Madrid: Visor, 2016.

Carrera, Tania. Un dios lubricante. 2015. Un dios lubricante. Medio de publicación (web). <http://undioslubricante.com/>. Consultado 8 my. 2018.

Campos, Marco Antonio. Antología. La poesía del siglo XX en México. Madrid: Visor, 2009.

Castillo, Rodrigo. Sombra roja. Diecisiete poetas mexicanas (1964-1985). Madrid: Vaso Roto, 2016.

CHouciño, Ana. «De la ironía al silencio: sobre la melancolía en Jaime Sabines». Literatura Mexicana. 29:2 (2018): 111-132. UNAM. Medio de publicación (web). <https://revistas-filologicas.unam.mx/literatura-mexicana/index.php/lm/article/view/1132>. Consultado 5 jul. 2018.

Clark, Ben. Los hijos de los hijos de la ira. Madrid: Hiperión, 2006.

Clark, Ben. Los últimos perros de Shackleton. México: Proyecto Literal, 2013.

Clark, Ben. La policía celeste. Madrid: Visor, 2018.

Clark de Lara, Belem. "¿Generaciones o constelaciones?». Belem Clark de Lara y Elisa Guerra (coords.). La república de las letras: asomos a la cultura escrita del México decimonónico. México: Universidad Nacional Autónoma de México. 1 (2005): 11-46.

Díez-Canedo F., Joaquín. "Algunas consideraciones sobre la edición universitaria». Encuentros 2050. 16 (abril 2018): 37-39. Encuentros 2050. Medio de publicación (web). <https://encuentros 2050. files.wordpress.com/2018/04/03_encuentros2050_ abril2018_pdfwp.pdf>. Consultado 23 my. 2018.

Jorge Esquinca, Tedi López Mills y Myriam Moscona. México 20. La nouvelle poésie mexicaine, Prólogo de Philippe Ollé-Laprune, traducción de Jean-Luc Lacarriere y Joani Hocquenghem. Paris: Le Castor Astral / Secretaría de Cultura de México, 2016.

Flores, Malva. El ocaso de los poetas intelectuales y la "generación del desencanto". Xalapa: Universidad Veracruzana, 2010.

Flores, Malva. "Me alegra mucho por el gran gran Lizalde. Dijo Manuel Iris: "El premio Carlos Fuentes mereció un Lizalde. Felicidades a él." Y suscribo». En Facebook. 8 de noviembre de 2016. Facebook. Medio de publicación (web). <https://www.facebook. com/malva.flores/posts/10154666087124437>. Consultado 7 my. 2018.

Francos, Aitor. «Entrevista a Juan Carlos Bautista». La Galla Ciencia. 1 de abril de 2017. La Galla Ciencia. Medio de publicación (web). <http://aitorfrancos. lagallaciencia.com/2017/04/entrevista-juan-carlosbautista.html>. Consultado 11 my. 2018.

García, Esther M. Bitácora de mujeres extrañas. México: Consejo Nacional para la Cultura y las Artes, 2014.

García, Esther M. Mamá es un animal negro que va de largo por las alcobas blancas. Toluca: Universidad Autónoma del Estado de México, 2017. UAEMex. Medio de publicación (web). <http://ri.uaemex.mx/ handle/20.500.11799/67447>. Consultado 7 my. 2018.

García Cueto, Pedro. Juan Gil-Albert y el exilio espanol en México. Valencia: Biblioteca Valenciana Nicola Primitiu, D. L., 2016. Cervantes Virtual. Medio de publicación (web). <http://www.cervantesvirtual. com/portales/san_juan_de_la_cruz/obra/juan-gilalbert-y-el-exilio-espanol-en-mexico-texto-impreso/>. Consultado 29 ag. 2018.

García, Luis Eduardo, Diana Garza Islas, Daniel Bencomo, Yolanda Segura y Jorge Posada. Poesía Mexa. Poesía Mexa. Medio de publicación (web). $<$ https://poesiamexa.wordpress.com/>. Consultado 8 my. 2018.

Gil de Biedma, Jaime. Poemas póstumos. Madrid: Poesía Para Todos, 1968.

Herbert, Julián. Canción de tumba. Barcelona: Mondadori, 2011.

Hernández, Francisco. Mar de fondo. México: Joaquín Mortiz, 1982.

Higashi, Alejandro. "Hitos provisionales en el perfil de una generación: poetas mexicanos nacidos entre 1975 y 1985». Literatura Mexicana. 25 (2014): 49-74. Science Direct. Medio de publicación (web). <https://www.sciencedirect.com/science/article/pii/ S0188254614726121>. Consultado 19 en. 2016.

Higashi, Alejandro. PM /XXI/360 ${ }^{\circ}$. Crematística y estética de la poesía mexicana contemporánea en la era de la tradición de la ruptura. México: Tirant Humanidades / Universidad Autónoma Metropolitana, 2015.

Illán, Noelia, Joaquín Baños, Vanessa Castaño, Samuel Jara, Daniel J. Rodríguez y Sara J Trigueros. La Galla Ciencia. La Galla Ciencia. Medio de publicación (web). <http://www.lagallaciencia.com/p/quienessomos.html>. Consultado 8 my. 2018.

Landa, Josu. "La poesía en el planeta de los nimios». Julián Herbert, Javier de la Mora y Santiago Matías (comps.). Escribir poesía en México. México: Bonobos, 2010. 
Medel, Elena y Luna Miguel. Los reyes subterráneos. Veinte poetas jóvenes de México. Córdoba: La Bella Varsovia, 2015.

Orinuela, Antonio. 21 Balas: Antología de poesía mexicana actual. Madrid: Agencia Española de Cooperación Internacional para el Desarrollo / Fundación Juan Ramón Jiménez / If Ediciones / Solar Servicios Editoriales, 2009.

Pacheco, José Emilio. No me preguntes cómo pasa el tiempo. México: Joaquín Mortiz, 1969.

Palma Castro, Alejandro. «De la extrańeza al dificultismo: los monstruos de Gerardo Deniz». Michael J. McGrath (ed.), «This Spanish Thing». Essays in Honor of Edward F. Stanton. Newark, Delaware: Juan de la Cuesta-Hispanic Monographs, 2016: 221-236. Academia. Medio de publicación (web). <https://www. academia.edu/34143726/De_la_extra\%C3\%B1eza_ al_dificultismo_los_monstruos_de_Gerardo_Deniz>. Consultado 27 febr. 2018.

Paz, Octavio. El laberinto de la soledad. Madrid: Cátedra, 2014 [ed. or. 1993].

Peña, Christian. Me llamo Hokusai. México: Fondo de Cultura Económica / Instituto Cultural de Aguascalientes / Instituto Cultural de Bellas Artes / Consejo Nacional para la Cultura y las Artes, 2014.

Petisme, Ángel. El sur del tiempo (Antología poética 19842015). México: Sediento Ediciones, 2015.

Quirarte, Vicente. «Filiación y continuidad de la poesía mexicana reciente». Cuadernillo 23, Ediciones de la revista Punto de Partida, 11-16 (marzo 1982).

Ramírez Vuelvas, Carlos. Mexican Drugs. Cultura popular y narcotráfico. Madrid: Lengua de trapo, 2011.

Reynosa, Minerva. Mammut. Concretoons Cartuchera, 2015. Cartuchera. Medio de publicación (web). <http://cartuchera.concretoons.com/index.html>. Consultado 8 my. 2018.

Rivera, Silvia Tomasa. En el huerto de Dios. Monterrey: Universidad Autónoma de Nuevo León, 2014.

Rodrigo, Balam. Libro centroamericano de los muertos. México: Fondo de Cultura Económica / Instituto Cultural de Aguascalientes / Instituto Nacional de Bellas Artes, 2018.

Salgado, Armando y José Agustín Solórzano. Parkour pop.ético (o cómo saltar las bardas hacia el poema). México: Secretaría de Educación Pública, 2017. Secretaría de Educación Pública. Medio de publicación (web). <https://www.dgespe.sep.gob.mx/public/ gaceta/Parkour_pop_etico.pdf $>$. Consultado $8 \mathrm{my}$. 2018.

SÁnchez, María. Cuaderno de campo. Córdoba: La Bella Varsovia, 2018 [ed. or. 2017].

Serrano, Pedro y Carlos López Beltrán (comps). 359 Delicados (con filtro). Antología de la poesía actual en México. Santiago de Chile: Ediciones LOM, 2012.

VV.AA. Fuego de dos fraguas: poetas jóvenes de México y España. México: Exmolino: Taller Editorial / Centro Cultural España, 2016.

Villarreal, Minerva Margarita. Las maneras del agua. México: Fondo de Cultura Económica / Instituto Cultural de Aguascalientes / Instituto Nacional de Bellas Artes, 2016.

De Villena, Luis Antonio. «Algunos apuntes sobre la poesía joven de ahora mismo". Entre Ríos. Revista de Arte y Letras. Granada, s. f. Luis Antonio de Villena. Medio de publicación (web). <http://luisantoniodevillena.es/web/articulos/algunos-apuntes-sobre-lapoesia->. Consultado 11 my. 2018. 